\title{
The influence of time of elimination communication on the prevalence of infantile daytime urination control - a survey from Mainland China
}

\section{JianJian Wang}

The First Affiliated Hospital of Zhengzhou University

\section{Yan Wang}

The First Affiliated Hospital of Zhengzhou University

\section{Yi He Wang}

The First Affiliated Hospital of Zhengzhou University

\section{Yi Bo Wen}

The First Affiliated Hospital of Zhengzhou University

\section{Chun Zi Jiang}

The First Affiliated Hospital of Zhengzhou University

Jian Guo Wen ( $\nabla$ wenjg0@hotmail.com )

The First Affiliated Hospital of Zhengzhou University

\section{Research article}

Keywords: children and adolescent, elimination communication, urination control, disposable diaper

Posted Date: March 18th, 2020

DOl: https://doi.org/10.21203/rs.3.rs-17650/v1

License: (9) (i) This work is licensed under a Creative Commons Attribution 4.0 International License. Read Full License 


\section{Abstract}

Background: Child self-administration of urination is one of the most challenging stages of development in early childhood, and it is also an important manifestation of family development in parenting. But a pilot survey shows that urination control has decreased significantly during the past decade in Mainland China.Whether it is related to delay of elimination communication (EC) is unclear.

Methods A cross-sectional study in children (aged 3-10 years) was performed by distributing 10010 anonymous self-administered questionnaires to parents in Mainland China from March to September 2017. T The questionnaires included sociodemographic data,caregivers' information,and details about the disposable diapers (DD) usage,EC commencement date.

Results A total of 8629 ( $86.22 \%$ ) children were qualified to enter the final statistical analysis. The urinary control rates at 2 years old in children with EC starting before 12 months of age was significantly higher than those who start after 12 months of age ( $70.72 \%$ vs $59.02 \%, p<0.001)$,and significantly higher than those no EC ( $70.72 \% v s 42.48 \%, p<0.001)$. In addition,there was no significant difference in the rate of urinary control at 2 years old between the subgroups at different EC start times within 12 months. After 12 months, the urinary control rate at 2 years old of different subgroups decreased with the start time of EC, which were: $59.97 \%$ and $54.10 \%$. The results of urinary control rates at several other ages (ie, 0.5 years, 1 year,and 1.5 years) are similar to those at 2 years of age. There was no difference between groups of different genders. The later the beginning of EC, the lower the urination control was found . EC helps infants move quite easily into traditional toilet training when they are old enough.

Conclusions Infants and young children start EC as soon as possible at the age of 3 to 12 months is conducive to the development of daytime urination control. A later onset of EC may be risk factors for urination control.

\section{Background}

Child self-administration of urination is one of the most challenging stages of development in early childhood, and it is also an important manifestation of family development in parenting. Toilet training plays an important role in obtaining self-urinary control. However, from the literature review, many countries still have different time to start toilet training. European and American countries advocate infants and children to start toilet training after 2 years of age. ${ }^{1,2}$ For example, the "Guide to Toilet Training" published by the American Academy of Pediatrics(AAP) does not recommend infants to toilet training before the age of $2 .^{3}$ In the past, China had the traditional habit of EC(use less DD and start toilet training earlier than in Western countries), which enabled $70.55 \%$ of young children to get urinary control around 2 years old. ${ }^{4}$ It is also worth noting that since he 1970s, the worldwide popularity of diapers (also known as disposable diaper) and changes in the concept of toilet training have had a deeper impact on countries around the world. It has also had a great impact on China, which is experiencing rapid economic development. The use of DD in China has become more and more common, and there has also 
been a change in the concept of parenting. However, it is still controversial when it is more beneficial to start toilet training (i.e. EC) for urination control. Some clinical experts increasingly recognize that longtime dependence on diapers and delayed EC and toilet training is associated with an unstable bladder, urinary frequency, urinary incontinence, and other elimination problems.

Recently,we showed in a pilot survey that many young parents no longer pay as much attention to EC in early childhood as their predecessors,and they are overly dependent on the diapers.Clinically,the number of children with dysuria is also gradually increasing. Whether this increase is related to timing of EC is unclear. In 2017, British Broadcasting Corporation(BBC) reported and encouraged that parents should start EC as early as possible.Such recommendations need supportive evidence.Obviously, the relationship between timing of EC and urination control needs to be investigated. The present study aims to verify whether urination control is related to the commencement of EC by a large-scale survey in children in Mainland China.

\section{Methods}

\section{Subjects}

From March to September 2017,an epidemiological survey of urination control among children and adolescent aged 3 to 10 years was performed in six prefecture-level cities of Henan provinces throughout Mainland China.S ix cities within the province were randomly sampled as the investigation areas, based on a list of all the geographic regions in the prefecture. Three of them are located in the north of the province (Anyang, Xinxiang, Jiaozuo), one in the south (Nanyang), one in the west (Luoyang) and one in the center (Zhengzhou). In each city, fifteen kindergartens, 15 primary schools in total were selected by means of systematic sampling including rural and urban areas,and classes were randomly chosen according to the children's age distribution in the school. Permission was obtained from the Ministry of Education and the municipal level Departments of Education of the 6 cities respectively. This study was performed according to the Zhengzhou University First Hospital approved Institutional Review Board protocol(IRB number: R-2017-LW-37).

\section{Methods}

The cross-sectional paper survey used a self-administered anonymous questionnaire consisting of 4 sections and required parents to 'tick-off' boxes. Section 1 collected the child's background data-date of birth, gender, and primary caregiver (including parents, grandparents and babysitters). Section 2 collected information on DD usage since birth by enquiring "Has your baby used DD since being born?" If parents answered "Yes," they were asked to indicate how long DD was used, and whether it was only at night or during day and night? Section 3 collected information on EC and the parent's attitude to voiding training. Section 4 investigated urination control information, including answers to"When does your child stop wetting his pants at daytime?" The parents were required to write down the date when their child ceased wetting (a dry period of at least 1 month). 
At the time of attending consultant conference at kindergarten or primary school, the parents of children were asked to fill up the questionnaire. The questionnaire was completed and returned to the investigator within one week. In order to collect data in an economical and reliably way, we adopted the method of using questionnaire which is similar to those employed by Dr. Wang QW. ${ }^{4}$

Definition of EC:When parents read bodily cues and body language,they hold the baby's legs up over a baby's toilet or bucket and make a cuing sound like "so-" or "en-,"to help the child release their waste away from their body. When able to walk, the child is helped or guided by parents to void in a toilet or in a place to mimic toilet voiding. EC Group : infants with EC were grouped according to the EC starting time (age).

\section{Statistical analysis}

Statistical analyses were performed using the Statistical Package for Social Sciences (SPSS),version 18.0 for windows. Qualitative data were expressed in terms of rates. Comparison of variables between different genders, caregivers, habitation, attitude to early toilet training,and EC were conducted by using $\chi 2$ tests or Fisher's exact tests when appropriate; Cochran-Armitage trend test was used for comparison of multiple rates. $p$-values of $<0.05$ were considered statistically significant. ORs and their corresponding $95 \% \mathrm{Cl}$ were calculated to measure associations. The original alpha value was set at 0.05 . To reduce the chance of obtaining type 1 errors from multiple analyses performed on the same dependent variable, Bonferroni-adjusted $p$-values were calculated by dividing the alpha value by the number of comparisons. Factors related to urination control were evaluated by logistic regression.

\section{Results}

A total of 10,010 children and adolescent aged $3-10$ years were investigated and 9,764 questionnaires were returned: $86.22 \%(8,629 / 10,010)$ of them qualified $\rrbracket a l l$ question is clearly answered $\Downarrow$ for statistical analysis. Among them,4,379 (50.75\%) were boys and 4,250 (49.25\%) were girls.

The urinary control rate was significantly associated with late onset of EC.The results of urinary control rate at 2 years old in different starting time of EC groups showed that the urinary control rate of EC before 12 months was significantly higher than that of EC after 12 months $\left(70.72 \%\right.$ versus $59.02 \%,{ }^{2}=105.220$ ه $\mathrm{P}<0.0001)$, also significantly higher than the urinary control rate of children without EC $(70.72 \%$ versus $\left.42.48 \%,{ }^{2}=316.697 \otimes \mathrm{P}<0.0001\right) \otimes$ Table $1 \bigotimes$. There was no significant difference in daytime urination control between boys and girls in every EC group.

The urination control rate of the subgroup at the age of 2 years before 12 months was $72.31 \%$, and $69.43 \%$, respectively. There was no significant difference between the subgroups $₫$ all $P>0.05 \rrbracket$. After 12 months, the urinary control rate of different subgroups decreased with the start time of EC, which was $59.97 \%$ and $54.10 \% \otimes T$ Table $2 \bigotimes$. According to the trend chi-square test, the urinary control rate of boys, girls and the whole at 2 years old decreased with the increase of EC start time, and there was a significant downward trend. The trends of different gender groups and subgroups were similar to the overall. 
At the same time, we found that the urinary control rate results of the different EC start time subgroups at 0.5, 1 year, 1.5 years old, and 2 years old were similar. That is, children who start EC before 12 months are significantly higher than those who start EC after 12 months. Also higher than children without EC(Table 3). The line graph in Figure 1 can more intuitively reflect this relationship.

All children began using DD immediately after birth. The urinary control in infants with DD usage in each group has no significant difference. Children cared for by parents receive better urination control than those of grandparents and babysitters at the age of 2 years $\left(67.24 \%\right.$ versus $63.06 \%$, and $62.62 \%,{ }^{2}=12.966$, $P<0.01)$. Similarly, the urinary control rate results of several other ages were similar to those at 2 years of age.

Possible risk factors including gender, childhood caregiver, habitation, attitude to early toilet training, and EC starting time with multi-level logistic regression analysis assessing determinants of urination control are shown in Table 4. Type of care-giver,and late EC onset, were risk factors of urination control $(p<0.01)$.

\section{Discussion}

It is generally believed that children's daytime urination control function gradually develops and matures when they are 2-3 years old. The association between toilet training and this physical development remains unproven. Toilet training involves not only complex nerve, muscle's participation and control, at the same time, its concept and practice are restricted by social culture custom and environmental material condition. ${ }^{5-7}$ Some conventional wisdom holds that bladder control development is an ongoing process of maturation, and that it is not possible to promote bladder development through toilet training. ${ }^{8}$ Brazelton ${ }^{9}$ described a toilet training for children in her 1962 study and emphasized the age of toilet training. They believe that the theory of children's toilet training focuses on the development of children's voluntary control of excretory function (that is, after the excretory function is fully developed), emphasizes flexibility and reduces the conflict and anxiety in training, so it is not necessary to start toilet training prematurely. It continues to influence parenting and toilet practices in contemporary American families. But that doesn't tell us that we have to train at about age 2 in accordance with their philosophy. Studies have confirmed the existence of synaptic neural pathways associated with bladder control

development after birth in mammals. ${ }^{10}$ Dr. JG Wen et al. ${ }^{11-13}$ using dynamic bladder pressure monitoring techniques combined with polysomnography also showed that the mechanism of awakening reflex during bladder expansion has been established in neonatal period. Recent studies in Belgium have shown that toilet training after the age of two or more can increase the risk of daytime urinary incontinence and infectious diseases and delay the ability to control urine. ${ }^{5}$ Yang SS' study found that early toilet training can acquire the ability to control urine during the day and at night earlier, and toilet training can not affect the normal bladder function, and can reduce the incidence of enuresis. ${ }^{2}$ All of these provide a theoretical basis for early toilet training.

In traditional Chinese (Asian) customs and concepts, parents in the past often began to EC(toilet training) after the baby was born. EC refers to the use of a special posture to help infants urinate:When parents 
read bodily cues and body language, they hold the baby's legs up over a baby's toilet or bucket and make a cuing sound like "so-" or "en-," to help the child release their waste away from their body. When able to walk, the child is helped or guided by parents to void in a toilet or in a place to mimic toilet voiding.

The present study points towards the fact that lack of early EC is associated with decreased daytime urination control meaning that early EC enables children to become diaper-free all-day much earlier than their peers who are only using diapers without early voiding training. EC helps infants move quite easily into traditional toilet training when they are old enough. In the study, it was found that the urinary control rate of children who started urinary training within 12 months after birth was $72.31 \%$ and $69.43 \%$ in the sub-group at the age of 2 , which was significantly higher than that after 12 months. The urinary control rates of infants who started EC after 12 months at 2 years of age were $59.97 \%$ and $54.1 \%$, respectively. The urinary control rate of each subgroup was similar at 0.5 years, 1 year, 1.5 years, and 2 years old, that is, the urinary control rate of the subgroups with EC before 12 months was significantly higher than the subgroup of ECs after 12 months and the group without EC. In other words, the earlier and longer the EC is, the more favorable it is to obtain urination control.

This study shows that infants and young children who use diapers begin to exercise EC(toilet training) before the age of 1 to facilitate the development of daytime urination control. The reason for this is that there are anatomical and pathophysiological foundations. The micturition reflex system initiates in the brainstem while bladder emptying is a spinal reflex that is not controlled by the brain in newborns and young infants; with maturation of the central nervous system (CNS), the cerebral cortex gradually assumes conscious control of micturition, so in theory early toilet training should help in children's urination control. ${ }^{14}$ Additionally, many studies have shown that the newborn's brain has joint or partially joint control of voiding. ${ }^{11,15}$ The connections between brain and bladder are already established in newborns. Babies are aware of their elimination needs from birth and communicate those needs through various vocal and bodily signals, the relationship between voiding patterns and brain activity in healthy preterm neonates using video-electroencephalo-graph (video-EEG) has been established. ${ }^{13}$ This connection between the CNS and bladder or voiding control, forms the basis of voiding training. By taking babies to appropriate elimination places during infancy, we enable them to maintain a connection with their bodily sensations and learn from an early age what to do when they experience those sensations. ${ }^{16}$ In fact, the basis of Chinese-style toilet training (i.e. EC) is that the baby can sense the meaning of urination, and will send a defecation signal to correlate the urinary movements, sounds and urination, form a conditional reflex, and practice continuously. Over time, the ability of infants to control urination will be synchronized with physical development and language development. The present study provided some evidence supporting that EC may be helpful for infants to acquire voiding control by establishing a reflex between the brain and the bladder.

Furthermore,Joinson comparing children who started toilet training (i.e. EC) between 15 and 24 months to children starting toilet training after 24 months and found that late training was associated with higher odds of persistent daytime wetting. ${ }^{17}$ Children may become used to the feeling of wearing DD and may 
develop manifestations of dependence, making them resistant to toilet training. Thus, to establish a reflex between brain and bladder, starting EC earlier seems to be important. It can be practiced by stay-at-home or working parents. EC can be undertaken by people of all income levels and physical abilities. ${ }^{18}$ China has a history of early EC lasting thousands of years, and until at least ten years ago, Chinese parents continued this traditional way of toilet training. In 2006, we published a cross-sectional survey showing the prevalence of attaining urinary control rate was $52 \%$ in one-year old children and $70 \%$ in two-year-olds after EC, indicating that by using EC most Chinese infants developed voiding control by two years[4]. Most children begin kindergarten at 2-3 years of age in Mainland China. It is very beneficial for children to become dry by the time they enter kindergarten. Although it would be easier for parents to commence toilet training when their children have developed an increased ability to act and behavior, this would not be acceptable for children of primary school age (5-7 years old). Therefore, guidelines for starting EC after 18 months would not be acceptable for most Chinese children and parents.

In addition, it is well known that the infant's physical development is incomplete within 3 months, especially the spine and neck are still fragile. If EC is performed at this time, it may increase the risk of various accidents of the infant and is not conducive to the growth and development of the infant. However, since infants can complete their head-up behavior after 3 months, this indicates that they are eligible for EC. Therefore, it is more suitable for EC after 3 months. We also found in the survey that children who are taking EC also start three months after birth, while children without EC did not carry out other toilet training.Parents of these children without EC may only use DD for reasons such as busy work.

Finally, considering the huge Chinese population in Mainland China with varying climates, different living habits, and unbalanced regional economic development, the samples and area investigated in the present study cannot represent all children and territory throughout China. An international multi-center project involving more countries is recommended to provide stronger documentation to update present guidelines using DD and EC, not only in Mainland China but worldwide.

\section{Conclusions}

In the case of the use of DD,infants and young children start EC as soon as possible at the age of 3 to 12 months is conducive to the development of daytime urination control, which can help children achieve good daytime urination control at the beginning of kindergarten life, and is more in line with China's national conditions.

\section{Abbreviations}

EC: Elimination communication; DD: Disposable diapers; AAP: American Academy of Pediatrics; BBC: British Broadcasting Corporation; SPSS: Statistical Package for Social Sciences; CNS: Central nervous system; EEG: electroencephalo-graph.

\section{Declarations}




\section{Ethics approval and consent to participate}

All procedures performed in studies involving human participants were in accordance with the ethical standards of the institutional research committee and with the 1964 Helsinki declaration and its later amendments or comparable ethical standards. This study received institutional board approval by the ethics committee at Zhengzhou University First Hospital (IRB number: R-2017-LW-37). For this type of retrospective study formal consent is not required.

\section{Consent for publication}

Not applicable.

\section{Availability of data and materials}

The datasets used and/or analysed during the current study are available from the corresponding author on reasonable request.

\section{Competing Interests}

The authors declare that they have no competing interests.

\section{Funding}

Not applicable

\section{Author contributions}

JJW developed the concepts, study design, obtained grant funding and ethical Approvals. YW, and JGW were also associated in concepts. JJW, YHW, YBW, and CZJ performed data acquisition. JJW, and CZJ performed data analysis. JJW, and YHW performed statistical analysis and interpretation. JGW provided guidance with mathematical concepts and analytical algorithms. YBW performed data verification and interpretation. JJW created figures and tables. JJW, and JGW were involved with manuscript writing, editing, and approval of final version. All authors have read and approved the manuscript.

\section{Acknowledgments}

Many thanks to the children and caregivers who participated in the study. Many thanks to the Nurses department from the First Affiliated Hospital of Zhengzhou University, Zhengzhou Children's Hospital, and Xinyang Centre Hospital for their support in making this survey.

\section{Author details}

${ }^{1}$ Henan Joint International Pediatric Urodynamic Laboratory, Pediatric Urodynamic Centre of the First Affiliated Hospital of Zhengzhou University, Zhengzhou, Henan Province, China; 
${ }^{2}$ Department of Urology, The First Affiliated Hospital of Zhengzhou University, Zhengzhou, Henan Province, China

\section{References}

1. Van Der Cruyssen K, De Wachter S, Van Hal G, et al. The voiding pattern in healthy pre- and term infants and toddlers: a literature review. Eur J Pediatr. 2015;174:1129-1142.

2. Yang SS, Zhao LL, Chang SJ. Early initiation of toilet training for urine was associated with early urinary continence and does not appear to be associated with bladder dysfunction. Neurourol Urodyn. 2011;30:1253-2357.

3. Wolraich ML, Tippins S. Guide to toilet training(American Academy of Pediatrics). 4th ed.New York:Bantam Dell. 2003:2-9.

4. Wen JG, Wang QW, Wen JJ, et al. Development of nocturnal urinary control in Chinese children younger than 8 years old. Urology. 2006;68:1103-1108.

5. Van Nunen K, Kaerts N, Wyndaele JJ, et al. Parents' views on toilet training (TT): A quantitative study to identify the beliefs and attitudes of parents concerning TT. J Child Health Care. 2015;19:265-274.

6. Von Gontard A, De Jong TP, Badawi JK, et al. Psychological and physical environmental factors in the development of incontinence in adults and children: a comprehensive review. J Wound Ostomy Continence Nurs. 2017;44:181-187.

7. Qian Y. Correlation analysis of toilet training and temperament dimensions in preschool children. $J$ Nurs. 2017;24:22-25.

8. Hodges SJ, Richards KA, Gorbachinsky I, et al. The association of age of toilet training and dysfunctional voiding. Res Rep Urol. 2014;6:127-130.

9. Brazelton TB. A child-oriented approach to toilet training. Pediatrics. 1962;29:121-128.

10. De Groat WC, Griffiths D, Yoshimura N. Neural control of the lower urinary tract. Compr Physiol. 2015;5:327-396.

11. Wen JG, Lu YT, Cui LG, et al. Bladder function development and its urodynamic evaluation in neonates and infants less than 2 years old. Neurourol Urodyn. 2015;34:554-560.

12. Zhang Y, Wen JG, Wang J,et al. Study on cortical arousal at voiding in term and preterm newborns monitored by electroencephalogram. Chin J App/ Clin Pediatr. 2015:1069-1071.

13. Zhang YS, Huang CX, Wen JG, et al. . Relationship between brain activity and voiding patterns in healthy preterm neonates. J Pediatr Urol. 2016;12:113-119.

14. Thiel M, Bezerra ES, Thiel RR, et al. Re: Yang SS-D, Zhao L-L, and Chang S-J. Early initiation of toilet training for urine was associated with early urinary continence and does not appear to be associated with bladder dysfunction. Neurourol Urodyn. 2011;30:1253-1257.

15. Yeung CK. The normal infant bladder. Scand J Urol Nephrol 1995;173:19-23.

16. Boucke L. Infant potty training: A gentle and primeval method adapted to modern living. Lafayette, CO: White-Boucke Publishing, Inc. 2000. 
17. Joinson C, Heron J, Von Gontard A, et al. A prospective study of age at initiation of toilet training and subsequent daytime bladder control in school-age children. J Dev Behav Pediatr. 2009;30:385-393.

18. Thaman LA, Eichenfield LF. Diapering habits: a global perspective. Pediatr Dermatol. 2014;31:15-18.

\section{Tables}

Table 1 - The daytime urination control at the age of 2 in each group

\begin{tabular}{|c|c|c|c|c|c|c|c|c|}
\hline \multirow{2}{*}{$\begin{array}{l}\text { EC starting } \\
\text { time (months) }\end{array}$} & \multicolumn{2}{|l|}{ Boys } & \multicolumn{2}{|l|}{ Girls } & \multicolumn{2}{|c|}{ Total } & \multirow[t]{2}{*}{$\chi^{2}$} & \multirow[t]{2}{*}{$\mathrm{P}^{*}$} \\
\hline & $\begin{array}{c}\text { Observed total } \\
\text { number } \square \mathrm{n} \square\end{array}$ & $\begin{array}{c}\text { Actual control } \\
\text { cases } ₫ \% \square\end{array}$ & $\begin{array}{c}\text { Observed total } \\
\text { number } \square \mathrm{n} \square\end{array}$ & $\begin{array}{c}\text { Actual control } \\
\text { cases } \square \% \square\end{array}$ & $\begin{array}{l}\text { Observed total } \\
\text { number } \square \mathrm{n} \square\end{array}$ & $\begin{array}{c}\text { Actual control } \\
\text { cases } \square \% \square\end{array}$ & & \\
\hline $3 \leq t<12$ & 2480 & $1785 \square 71.98 \square$ & 2407 & $1690 \square 70.21 \square$ & 4914 & $3475 \square 70.72 \square$ & 1.850 & 0.174 \\
\hline $12 \leq t<24$ & 1352 & $815 \square 60.28 \square$ & 1266 & 730ロ57.66凸 & 2618 & $1545 \square 59.02 \square$ & 1.854 & 0.173 \\
\hline no EC & 520 & $218 \square 41.92 \square$ & 577 & $248 \llbracket 42.98 \square$ & 1097 & $466 \llbracket 42.48 \square$ & 0.125 & 0.723 \\
\hline
\end{tabular}

*Asymp. Sig. with Chi-Square test on the daytime urination control between boys and girls in different age groups

Table 2 - The daytime urination control at the age of 2 in each subgroup 


\begin{tabular}{|c|c|c|c|c|c|c|c|c|c|}
\hline \multirow{2}{*}{$\begin{array}{c}\text { EC starting } \\
\text { time (months) }\end{array}$} & \multicolumn{2}{|l|}{ Boys } & \multicolumn{3}{|c|}{ Girls } & \multirow[b]{2}{*}{$\begin{array}{c}\text { Observed total } \\
\text { number } \square \mathrm{n} \square\end{array}$} & Total & \multirow[t]{2}{*}{$\chi^{2}$} & \multirow[t]{2}{*}{$\mathrm{P}^{*}$} \\
\hline & $\begin{array}{c}\text { Observed total } \\
\text { number } \square \mathrm{n} \square\end{array}$ & $\begin{array}{c}\text { Actual control } \\
\text { cases } \square \% \square\end{array}$ & $\begin{array}{r}\text { Obser } \\
\text { num }\end{array}$ & $\begin{array}{l}\text { otal } \\
\mathrm{n}\end{array}$ & $\begin{array}{c}\text { Actual control } \\
\text { cases } \square \% \square\end{array}$ & & $\begin{array}{c}\text { Actual control } \\
\text { cases } \square \% \square\end{array}$ & & \\
\hline $3 \leq \mathrm{t}<6$ & 1133 & $828(73.08)$ & 1063 & $760 \square$ & $71.50 \square$ & 2196 & 1588ロ72.31ם & 0.873 & 0.350 \\
\hline $6 \leq t<12$ & 1374 & $957(69.65)$ & 1344 & $930 \square$ & $69.20 \square$ & 2718 & 1887ロ69.43凸 & 0.066 & 0.797 \\
\hline $12 \leq t<18$ & 1114 & $680 \square 61.04 \square$ & 1077 & 634 & 58.87ロ & 2191 & 1314ロ59.97】 & 1.078 & 0.299 \\
\hline $18 \leq t<24$ & 238 & $135 \square 56.72 \square$ & 189 & $96 \square 5$ & $0.79 \square$ & 427 & $231 \square 54.10 \square$ & 1.491 & 0.222 \\
\hline no EC & 520 & $218 \square 41.92 \square$ & 577 & 248 & 42.98[ & 1097 & 466ロ42.48』 & 0.125 & 0.723 \\
\hline
\end{tabular}

*Asymp. Sig. with Chi-Square test on the daytime urination control between boys and girls in different age groups.

$\mathrm{p}<0.001$ with Cochran-Armitage Trend Test $\left(\chi^{2}=52.632\right)$ on the daytime urination control in the different EC starting time group of Chinese boys; $\mathrm{p}<0.001$ with Cochran-Armitage Trend Test $\left(\chi^{2}=64.195\right)$ on the daytime urination control in the different EC starting time group of Chinese girls; $p<0.001$ with Cochran-Armitage Trend Test $\left(\chi^{2}=115.323\right)$ on the daytime urination control in the different EC starting time group of all children;

Table 3 Daytime urination control in each group of infants at the same age

\begin{tabular}{|c|c|c|c|c|c|c|c|c|c|}
\hline $\begin{array}{l}\text { 'ting } \\
\text { Inths) }\end{array}$ & $\begin{array}{c}\text { Observed total } \\
\text { number } \square \mathrm{n} \rrbracket\end{array}$ & 0.5 yrs & & & $\begin{array}{c}1 \\
\text { yrs }\end{array}$ & $1.5 \mathrm{yl}$ & & \multicolumn{2}{|c|}{2 yrs } \\
\hline & 2718 & 92 & 3.38 & 610 & 22.44 & 1293 & 47.57 & 1887 & 69.43 \\
\hline & 2191 & 71 & 3.24 & 301 & 13.74 & 787 & 35.92 & 1314 & 59.97 \\
\hline & 427 & 13 & 3.05 & 55 & 12.88 & 118 & 27.63 & 231 & 54.1 \\
\hline
\end{tabular}

Table 4 Risk factors related to urination control at the age of 2 years 


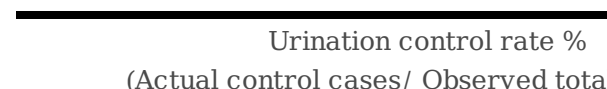

(Actual control cases/ Observed total number)

B

$\chi^{2}$

P

\begin{tabular}{|c|c|c|c|c|c|c|}
\hline & 64.35(2818/4379) & 1(ref) & & & 1(ref) & \\
\hline & $62.78(2668 / 4250)$ & -0.016 & 2.314 & 0.128 & 0.768 & $0.581-1.067$ \\
\hline \multicolumn{7}{|l|}{$\mathrm{n}$} \\
\hline & 63.13(2889/4576) & 1 (ref) & & & 1 (ref) & \\
\hline & 64.08(2597/4053) & 0.047 & 0.824 & 0.364 & 1.132 & $0.713-1.984$ \\
\hline \multicolumn{7}{|l|}{ r } \\
\hline & $67.24(4312 / 6413)$ & 1 (ref) & 12.966 & 0.002 & 1 (ref) & \\
\hline ats & 63.06(1330/2109) & 0.134 & 0.346 & 0.541 & 0.817 & $0.486-1.573$ \\
\hline $\mathrm{r}$ & $62.62(67 / 107)$ & -0.152 & 0.412 & 0.526 & 1.195 & $0.674-2.016$ \\
\hline \multicolumn{7}{|l|}{$\mathrm{EC}$} \\
\hline & $64.20(4362 / 6794)$ & 1(ref) & & & 1 (ref) & \\
\hline & 62.94(1155/1835) & -0.062 & 0.996 & 0.318 & 1.067 & $0.935-1.237$ \\
\hline \multicolumn{7}{|c|}{ of EC } \\
\hline & 72.31(1588/2196) & 1 (ref) & 352.250 & $<0.001$ & 1(ref) & \\
\hline & $69.43(1887 / 2718)$ & 1.103 & 162.263 & $<0.001$ & 0.293 & $0.231-0.362$ \\
\hline & 59.97(1314/2191) & 0.943 & 86.547 & $<0.001$ & 0.362 & $0.287-0.449$ \\
\hline & $54.10(231 / 427)$ & 0.784 & 63.452 & $<0.001$ & 0.487 & $0.376-0.563$ \\
\hline
\end{tabular}

\section{Figures}

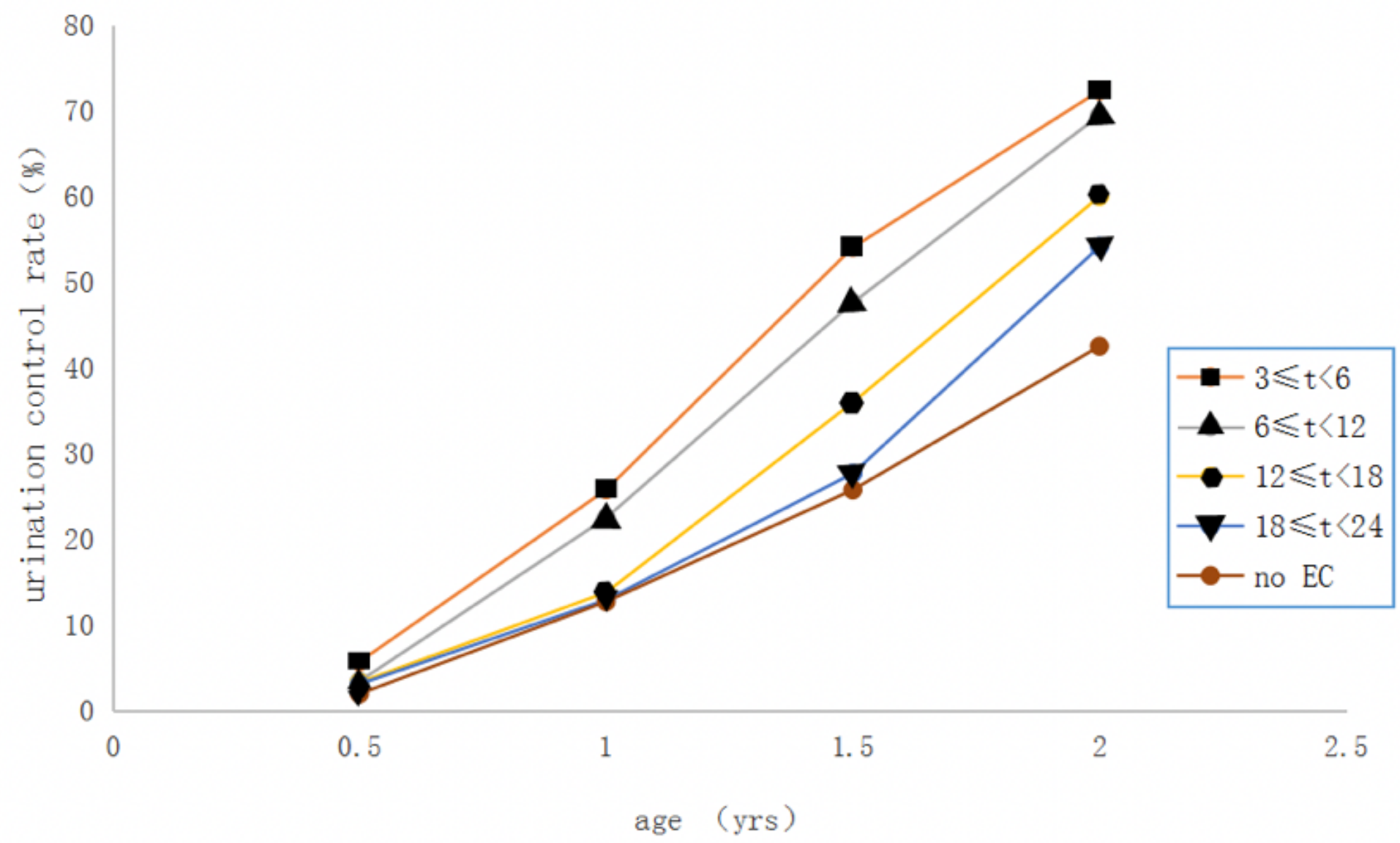




\section{Figure 1}

The starting time of elimination communication (EC) and their relationship to daytime urination control. In the case of the use of DD, the urination control rate of the subgroup at the age of 2 years before 12 months was significantly higher than those who start after 12 months of age, and also higher than those no EC, which was $(72.31 \%$ and $69.43 \%$ ) vs ( $59.97 \%$ and $54.10 \%)$ vs( $42.48 \%)$. The later the beginning of $\mathrm{EC}$ is begun, the lower the daytime urination control. The results of urinary control rates at several other ages (ie, 0.5 years, 1 year, and 1.5 years) are similar to those at 2 years of age. ( $3 \leq t<6=$ starting age $\geq 3$ months but $<6$ months, $6 \leq \mathrm{t}<12=$ starting age $\geq 6$ months but $<12$ months, $12 \leq \mathrm{t}<18=$ starting age $\geq 12$ months but $<18$ months, $18 \leq \mathrm{t}<24=$ starting age $\geq 18$ months but $<24$ months, no $E C=$ never carried out $\mathrm{EC})$.

\section{Supplementary Files}

This is a list of supplementary files associated with this preprint. Click to download.

- STROBEchecklistcrosssectional.docx 